\title{
A INSTRUMENTALIZAÇÃO DA EDUCAÇÃO BRASILEIRA: A REFORMA DO ENSINO MÉDIO
}

\author{
LA INSTRUMENTALIZACIÓN DE LA EDUCACIÓN BRASILEÑA: LA REFORMA DE LA \\ ENSEÑANZA MEDIA
}

\section{THE INSTRUMENTALIZATION OF BRAZILIAN EDUCATION: THE HIGH SCHOOL EDUCATION REFORM}

\author{
Nayara Ferreira Costa ${ }^{1}$ \\ Mauro Gomes da Costa ${ }^{2}$ \\ Paula Naranjo da Costa ${ }^{3}$ \\ Ana Cláudia Sá Lima ${ }^{4}$
}

Resumo: A reforma do ensino médio sancionada pela Lei n¹3.415/2017 é oriunda da impositiva Medida Provisória 746 do governo Temer que visava a progressiva extinção das disciplinas de teor crítico, além de dar ênfase à formação de mão-de-obra barata para o mercado de trabalho, respondendo aos anseios do Banco Mundial. Após a análise documental da Lei de Diretrizes e Bases da Educação Nacional - LDB 9394/1996 é possível inferir que as imposições sofridas à educação brasileira por meio da reforma do Ensino Médio regridem à época ditatorial, de caráter tecnicista e conservador favorecendo a precarização e a privatização da educação brasileira.

Palavras-chave: Reforma do Ensino Médio. Imposição. Lei nº13.415/2017.

Resumén: La reforma de la Enseñanza Media por la Ley no 13.415/2007 viene de la imponente Medida Provisional 746 del gobierno Temer, que apunta a la progressiva extinción de las disciplinas de contenido critico, además de dar énfasis a la formación de mano de obra barata para el mercado de trabajo, respondiendo a los anhelos del Banco Mundial. Después del análisis documental de la Ley de Directrices y Bases de la Educación Nacional - LDB 9394/1996 es posible inferir que las imposiciones sufridas a la educación brasileña por medio de la reforma de la Enseñanza Media retroceden a los tiempos dictatoriales, de carácter tecnicista y conservador favoreciendo la precarización y la privatización de la educación brasileña.

Palabras-llave: Reforma de la Enseñanza Media. Imposición. Ley n¹3.415/2017.

Abstract: The high school reform sanctioned by the law number 13.415/2017 is a fruit of the Provisional Measure 746 of Temer government that aims to the progressive extinction of critical contents subjects, furthermore giving emphasis to the formation of cheap manpower for the marketplace, answer to the World Bank longings. After the Law of Guidelines and Base of National Education 9394/1996 analysis is possible to conclude that the impositions suffered by the Brazilian education by the high school reform regress to the dictatorial age, with a technical and conservative character favoring the precariousness and the privatization of the Brazilian Education.

Keywords: High school education reform. Imposition. Law number 13.415/2017.

\section{Introdução}

O Ensino Médio forma com a Educação Infantil e o Ensino Fundamental os níveis que compõe a Educação Básica brasileira, que, por sua vez, também admite modalidades de ensino, como a educação técnica profissional. 
Ocorre que após o golpe parlamentar de 2016 (LOWY, 2016) sofrido pelo Brasil, o atual governo iniciou um processo de imposições e cortes sociais que terão repercussão para as gerações futuras, como, por exemplo, a Emenda Constitucional no 95/2016, chamada antes de sua promulgação de Proposta de Emenda Constitucional - PEC do Teto, que institui um novo regime fiscal e congela os investimentos públicos até 2036 numa manobra que na prática levará ao sucateamento de setores como a saúde e a educação, além de aprofundar as dificuldades de acesso a esses serviços essenciais.

Fato é que a escola brasileira, localizada no meio do fogo cruzado instaurado pelos cortes sociais não passaria ilesa por essas deformidades e retrocessos impostos no pós-golpe.

A exemplo disso pode se afirmar que a educação brasileira sofreu, desde a Medida Provisória MP n $n^{\circ} 746 / 2016$, uma imposição em caráter de urgência tendo como justificativa os índices abaixo do esperado nas avaliações que constituem o Sistema de Avaliação da Educação Básica - SAEB, um duro golpe: a promulgação da Lei no 13.415/2017 que reforma o ensino médio.

A esfera pública midiática - formadora, também, da opinião pública - busca, por sua vez, ludibriar a sociedade com a ideia de melhoria da educação por meio da possibilidade de maior inserção dos jovens no mercado de trabalho através da educação profissional e do fortalecimento do protagonismo juvenil na escola, mas que na verdade escondem o interesse no teor privatista da reforma (GAWRYZEWSKI, 2017).

Inclusive, o papel da mídia em apoio às reformas, educacionais, previdenciárias e trabalhistas, vem se tornando cada vez mais explícita desde a efetivação do golpe de 2016.

Em decorrência da promulgação da reforma do Ensino Médio de maneira impositiva e antidemocrática, buscou-se analisar o contexto atual da educação brasileira e as implicações do Golpe de 2016 para esse nível da educação básica por meio da Lei n ${ }^{\circ} 13.415 / 2017$ de modo a subsidiar reflexões posteriores e fortalecer movimentos de resistência entre os professores da educação básica e superior para ocupar os espaços deliberativos que foram usurpados por organizações com interesses privatistas no que tange a tomada de decisões acerca dos rumos da educação brasileira.

\section{A instrumentalização da educação brasileira}

Os processos de manipulação da educação brasileira foram criados para adequá-la aos anseios instrumentais ditados pelo banco mundial, o que fica explícito na exposição dos motivos da MP no746/2016, além disso, esse texto coloca o Amazonas como um exemplo de Estado que apresentou melhoras significativas nesse nível de ensino (BRASIL, 2016).

Todavia, o Ministério da Educação - MEC ao ressaltar os índices de ascensão no estado amazonense quer, com isso, ressaltar os ideais militaristas, visto que esse é o modelo progressivamente adotado por esse sistema de ensino. Inclusive, pode-se supor que esse fator contribuiu para a nomeação do ex-secretário de educação do Amazonas ao cargo de secretário de educação básica nacional, pois foi com ele que a militarização escolar teve forte apoio. 
A convergência entre os ideais militaristas e tecnicistas educacionais demonstram que as alterações impositivas da Reforma do Ensino Médio brasileiro servem apenas como uma adequação nas orientações legais e curriculares de modo aprofundar a formação de mão-de-obra barata para o mercado e desestimular o acesso ao ensino superior.

Manipular um tema de interesse social como a educação para fins privados pode ser considerado um produto da hegemonia da racionalidade instrumental. Para Habermas (2013) esse tipo de racionalidade hegemônica busca perenizar a dominação por meio de legitimação científica e tecnológica e, dessa forma, atingir todas as esferas da cultura.

Com o intuito de reduzir progressivamente o Ensino Médio de nível de ensino para uma modalidade, a saber, a educação profissional técnica, a Reforma do Ensino Médio torna marginal as finalidades dessa etapa de ensino ligadas à consolidação de saberes para subsidiar o prosseguimento dos estudos e a formação crítica.

Logo, o modelo tecnocrático/decisionista - baseado em aconselhamentos de especialistas científicos (HABERMAS, 2013) que está em voga no contexto educacional brasileiro pode ser percebido na seleção e imposição às escolas de listagens pré-estabelecidas, chamadas de direitos de aprendizagem, feitas por especialistas e solicitadas pelo MEC.

Além disso, a diminuição de espaços deliberativos na escola - no processo de escolha da língua estrangeira - deliberação que está em situação questionável pela forma de eleição dos gestores, que ainda em muitos locais - ocorre por meio de indicações (DRABACH; SOUZA, 2014) e somadas a minimização de um nível à uma modalidade profissionalizante irá relegar aos jovens de escola pública uma educação mínima e condições físicas/estruturais e formativas indignas (RAMOS; FRIGOTO, 2016).

A utilização instrumental da escola para formar mão-de-obra para o mercado de trabalho traz consigo o que Habermas (2013) chama de colonização do mundo da vida, isto é, uma coação à modernização das formas não instrumentais das esferas vitais, como o sistema escolar, tornando a vontade democrática supérflua frente aos interesses capitalistas/tecnocráticos.

Manipular a educação para fins instrumentais, alheios às necessidades da vida social dos estudantes, é uma tônica nas modificações realizadas nas orientações para o Ensino Médio por meio da reforma. As alterações impostas preveem que os atores sociais detentores do poder econômico regulem as orientações que subsidiam o fazer pedagógico, visto que a educação profissionalizante é usada como uma porta de acesso que:

Historicamente, a classe empresarial tem atuado para subordinar a escola pública às concepções que visam distanciar o conhecimento das necessidades humanas reais, sugerindo que o domínio amplo do saber sistematizado seria supérfluo à classe trabalhadora em função de suas necessidades imediatas de vida. Com efeito, a política educacional no Brasil tem reiterado a tendência de apropriação privada das formas mais desenvolvidas dos conhecimentos científicos, filosóficos e artísticos produzidos pela humanidade, o que se observa, inclusive, no âmbito das reformas curriculares (MARSIGLIA et al., 2017, p.112).

Silva (2015) afirma que o Ensino Médio terá um teor tecnocrata, visto que especialistas sob anuência do MEC construíram uma lista de conteúdos e habilidades aos moldes daqueles impostos pela 
ditadura-empresarial militar por meio da Lei $\mathrm{n}^{\circ}$ 5692/1971 (LEHER; VITTORIA; MOTTA, 2017). Obviamente, ela irá se configurar como um retrocesso da educação brasileira e aprofundará as dificuldades de acesso à cultura daqueles que dependem da educação pública, relegando a eles as imposições e necessidades do mercado.

A educação no pós golpe brasileiro começa a ser desenhada como um espaço de fomento da minimização do debate e do pensamento crítico. Logo, pode se afirmar que a reforma do ensino médio é legalmente funcional à hegemonia do status quo.

\section{A reforma do Ensino Médio: as imposições do golpe}

O fortalecimento das formas de colonização do mundo da vida pelos sistemas dinheiro e poder, na busca por ampliar e corrigir as suas formas de atuação dentro das instituições em que as práticas e as experiências de mundo são compartilhadas pelos atores sociais (HABERMAS, 2013), no contexto brasileiro, chegam até a escola por meio da facilitação do Estado e consequentemente obtém êxito ao modificar a legislação e os currículos de modo que sejam "corrigidos" os problemas da educação escolar.

Nessa perspectiva, a reforma foi criada para alterar a Lei no 9394/1996, Lei de Diretrizes e Bases da Educação Nacional - LDB e visa progressivamente tornar de tempo integral o Ensino Médio brasileiro, de modo que possam ser sanadas as dificuldades apresentadas na exposição dos motivos da MP n ${ }^{\circ} 746 / 2016$. O teor da reforma, no entanto, apresenta um caráter de adequação aos interesses do mercado para a formação de funcionários mais flexíveis e na possibilidade de prestação de serviços ao Estado, seja na forma de locação de prédios, seja na oferta de serviços educacionais ou em outras demandas criadas pela própria reforma.

No Art. 24 da LDB, que trata da organização dos níveis fundamental e médio, houve a inserção de um parágrafo, a partir da Lei nº13.415/2017, que aumenta a carga horária para o ensino médio e está assim disposto:

$\int 1^{\circ}$ A carga horária mínima anual de que trata o inciso I do caput deverá ser ampliada de forma progressiva, no ensino médio, para mil e quatrocentas horas, devendo os sistemas de ensino oferecer, no prazo máximo de cinco anos, pelo menos mil horas anuais de carga horária, a partir de 2 de março de 2017 (BRASIL, 2017).

No intuito de se adequar às alterações os sistemas de ensino deverão, por conta das implicações ora existentes, atentar contra o horário pedagógico de planejamento de ensino, em função do tempo ínfimo dado aos sistemas de ensino para compor os corpos docentes, além da possibilidade de superlotação de escolas que já tenham estrutura física para atender as demandas da promulgação da lei. Fato que ratifica a falta de discussão pública acerca dos processos deliberativos da reforma, com isto, ela já nasce fadada ao fracasso, ou talvez esse seja o intento da sua imposição.

Outro ponto crítico será em relação a possibilidade de haver um expressivo número de contratações de locações e serviços educacionais ligados à contratação de professores das áreas técnicas. Dessa forma, a realocação de verbas para a educação pública deverá voltar-se para a manutenção de empresas privadas e com isso fortalecer um processo de privatização educacional. 
No que tange a ampliação do horário no Ensino Médio Ramos e Frigotto (2016) assinalam que só existirá com o fim de melhoria dos índices do Brasil nas avaliações internacionais e a estratégia é "dar" mais aulas de Língua Portuguesa e Matemática, objetivo que, segundo os autores, demonstram que os resultados nas avaliações suplantam a importância da formação oferecida.

A reforma causou um aprofundamento do caráter subalterno da formação humana e democrática no contexto do Ensino Médio. Dentre as imposições da Lei nº13.415/2017 houve uma mudança específica que apresentou coerência com o governo Temer: a limitação dos espaços deliberativos dentro da escola no que tange a escolha das línguas estrangeiras que compõem os currículos do Ensino Médio. Junto ao agravo, a formação de atitudes democráticas foi imposta a obrigatoriedade do ensino da Língua Inglesa e, quando os sistemas de ensino tiverem condições de ofertar outro componente desta natureza que haja preferência pela Língua Espanhola.

O exercício e o fortalecimento de uma cultura antidemocrática a partir da promulgação da Reforma do Ensino Médio e a inserção do artigo 35 A é aviltante e desconsidera a diversidade cultural, o tamanho continental do país e as necessidades de comunidades fronteiriças. O descaso com as particularidades sociais na escolha do idioma a ser trabalhado na escola pode ser percebido na imposição curricular a seguir:

$\int 4^{\circ}$ Os currículos do ensino médio incluirão, obrigatoriamente, o estudo da língua inglesa e poderão ofertar outras línguas estrangeiras, em caráter optativo, preferencialmente o espanhol, de acordo com a disponibilidade de oferta, locais e horários definidos pelos sistemas de ensino (BRASIL, 2017).

Além do veto ao poder de decisão comunitário, a reforma restringiu o artigo 26 que tratava do currículo da educação básica, sobre o ensino da Arte, língua estrangeira, meio ambiente e que assim estava disposto:

$\int 2^{\circ} \mathrm{O}$ ensino da arte, especialmente em suas expressões regionais, constituirá componente curricular obrigatório nos diversos níveis da educação básica, de forma a promover o desenvolvimento cultural dos alunos.

$[\ldots]$

$\int 5^{\circ} \mathrm{Na}$ parte diversificada do currículo será incluído, obrigatoriamente, a partir da quinta série, o ensino de pelo menos uma língua estrangeira moderna, cuja escolha ficará a cargo da comunidade escolar, dentro das possibilidades da instituição.

$[\ldots]$

$\int 7^{\circ}$ Os currículos do ensino fundamental e médio devem incluir os princípios da proteção e defesa civil e a educação ambiental de forma integrada aos conteúdos obrigatórios (BRASIL, 1996).

A promoção do desenvolvimento cultural deixa de fazer parte da prática escolar amparada por lei, o que pode acenar para um cenário de diminuição de fomento aos programas que buscam desenvolver as capacidades artísticas e criadoras dos alunos, a redução de editais ou valores que buscam desenvolver cultura através de parcerias com as escolas públicas da educação básica, como o programa Novos Talentos, que visa apoiar propostas de atividades extracurriculares para professores e alunos da educação básica, financiado pela CAPES - Coordenação de Aperfeiçoamento de Pessoal de Nível Superior.

Com a nova redação da LDB a Educação Ambiental também teve sua importância relegada às possibilidades de integração com possíveis projetos fomentados pelos sistemas estaduais e municipais de 
ensino que, pelo menos até 2019, estarão ainda preocupados com as estruturas físicas e com os profissionais que atuarão nas escolas. A possibilidade de menor incentivo à formação nas áreas afetadas, bem como a marginalização da promoção de um desenvolvimento cultural dos alunos e o fomento às práticas de debate e fortalecimento de práticas democráticas ficam expostos com as imposições da Lei $\mathrm{n}^{\circ}$ 13.415/2017 da seguinte forma:

$\int 2^{\circ} \mathrm{O}$ ensino da arte, especialmente em suas expressões regionais, constituirá componente curricular obrigatório da educação básica.

$[\ldots]$

$\int 7^{\circ} \mathrm{A}$ integralização curricular poderá incluir, a critério dos sistemas de ensino, projetos e pesquisas envolvendo os temas transversais de que trata o caput (BRASIL, 2017).

Reis, Martins e Rosa (2017) afirmam que a alteração da LDB, no que tange a educação ambiental, gera uma preocupação acerca da pedagogia com a qual o tema será trabalhado nas áreas do conhecimento, visto que a prescrição dos objetos de conhecimento está extensa e o espaço a ser dado à educação ambiental não seja suficiente para abordar a temática em sua complexidade.

A reforma também inseriu o artigo 35-A que trata dos direitos e objetivos de aprendizagem do Ensino Médio. Nele é apresentado a definição das áreas do conhecimento, bem como os direitos e objetivos de aprendizagem desse nível de ensino, no entanto pode se afirmar que essa é uma forma de limitação do artigo 35 que aborda as finalidades do ensino médio. $\mathrm{O}$ artigo inserido pela Lei $\mathrm{n}^{\circ}$ 13.415/2017 está disposto dessa forma:

A Base Nacional Comum Curricular definirá direitos e objetivos de aprendizagem do ensino médio, conforme diretrizes do Conselho Nacional de Educação, nas seguintes áreas do conhecimento:

I - linguagens e suas tecnologias;

II - matemática e suas tecnologias;

III - ciências da natureza e suas tecnologias;

IV - ciências humanas e sociais aplicadas (BRASIL, 2017).

O caráter restritivo do artigo 35-A é percebido quanto à adequação do currículo às áreas do conhecimento priorizadas e cobradas no Exame Nacional do Ensino Médio - ENEM. Há, também, outras implicações nessa delimitação, uma delas é que a formação profissional será preconizada nas instituições públicas em função da ideia de maior inserção desses jovens no mercado de trabalho.

Entretanto, as escolas privadas que optarem por trabalhar visando a aprovação em vestibulares e no ENEM poderão formar estudantes para tal finalidade. As escolas públicas, por sua vez, voltarão seus esforços para os anseios do mercado e a formação de mão-de-obra para as indústrias por meio da reforma realizada de maneira impositiva pelo executivo federal e, quando muito, serão beneficiários de programas que visam reforçar um bom desempenho nas avaliações que compõem o SAEB. De uma forma ou de outra a formação humana será marginalizada, porque a educação pública vai formar mão-de-obra e a educação privada treinará alunos para acesso à educação superior.

Tais alterações se configuram como um "ataque” às conquistas realizadas no ensino médio pós LDB em vistas de retomar os princípios da Reforma Capanema ocorrida em 1940, conduzidas, também, em contextos antidemocráticos (RAMOS; FRIGOTTO, 2016). 
Nos parágrafos $6^{\circ}, 7^{\circ}$ e $8^{\circ}$ do artigo 35 A pode ser inferido que as alterações estarão ligadas com os processos de avaliação estabelecidos pela União, isto é, a base nacional será manipulada para priorizar não a melhoria dos processos educativos, mas a melhoria de índices.

O teor instrumental das alterações trazidas com a inserção do artigo 35-A espera que os alunos ao final do ensino médio aprendam uma profissão e a lógica do mercado, sejam formados ora para o domínio da ciência empirista, ora que sejam competentes no domínio da técnica para aqueles que usufruem das escolas profissionalizantes.

O país já viveu esse tipo de imposição e a escola profissionalizante era a opção dos mais pobres, tendo assim acesso a um ensino mínimo e uma vida igualmente mínima, tendo experimentado com isso o aumento das desigualdades (RAMOS; FRIGOTTO, 2016).

Neste cenário, serão concedidos certificados intermediários para estudantes do ensino médio profissionalizante de modo que haja a entrada do jovem o mais rápido possível no mercado de trabalho.

O currículo do Ensino Médio prioriza os itinerários formativos conforme as possibilidades de oferta dos sistemas de ensino, o que se configura como um aceno do executivo acerca do reconhecimento da impossibilidade de ajuste dos próprios sistemas em adequarem-se às imposições físicas e formativas implicadas pela reforma. Tais modificações ficaram dispostas da seguinte forma no artigo 36:

O currículo do ensino médio será composto pela Base Nacional Comum Curricular e por itinerários formativos, que deverão ser organizados por meio da oferta de diferentes arranjos curriculares, conforme a relevância para o contexto local e a possibilidade dos sistemas de ensino, a saber:

I - linguagens e suas tecnologias;

II - matemática e suas tecnologias;

III - ciências da natureza e suas tecnologias;

IV - ciências humanas e sociais aplicadas;

$\mathrm{V}$ - formação técnica e profissional.

$\int 1^{\circ}$ A organização das áreas de que trata o caput e das respectivas competências e habilidades será feita de acordo com critérios estabelecidos em cada sistema de ensino (BRASIL, 2017).

O acesso desigual à cultura em conjunto com a ideia de escolha pelos alunos dos itinerários formativos, que são limitados à disponibilidade dos sistemas de ensino, criará sobre os cursos de maior inserção no mercado de trabalho um aprimoramento de processos de seletividade e discursos meritocráticos onde a formação educacional não é nem de longe o interesse da escola. O que o ensino deve vivenciar após a implementação da reforma diz respeito a melhor programação da escola para a sua finalidade na sociedade capitalista: formar mão de obra barata.

Outro ponto para debate diz respeito a formação docente que sofrerá alterações formativas com a promulgação da Lei no 13.415/2017, pois se há um conjunto de críticas ao caráter impositivo acerca das listagens de conteúdos para os estudantes do Ensino Médio, estas implicações serão vividas também na Educação Superior, dentro das licenciaturas com a redução dos conteúdos críticos de seus currículos (RAMOS; FRIGOTTO, 2016).

Com isso, precarização do trabalho docente, a ser ofertado no Ensino Médio, preconizado por meio da reforma se exemplifica nos excertos retirados no artigo 61: 
IV - profissionais com notório saber reconhecido pelos respectivos sistemas de ensino, para ministrar conteúdos de áreas afins à sua formação ou experiência profissional, atestados por titulação específica ou prática de ensino em unidades educacionais da rede pública ou privada ou das corporações privadas em que tenham atuado, exclusivamente para atender ao inciso V do caput do art. 36;

$\mathrm{V}$ - profissionais graduados que tenham feito complementação pedagógica, conforme disposto pelo Conselho Nacional de Educação (BRASIL, 2017).

O inciso citado no parágrafo $4^{\circ}$ do artigo 61 refere-se à formação técnica e profissional e aos profissionais que atuarão no Ensino Médio público, esse parágrafo libera o "notório saber" como requisito para atuação docente, por sua vez essa abertura demonstra que a reforma trará implicações inclusive na política nacional de formação de professores, visto que isso desonera o estado de financiar e criar programas de apoio às licenciaturas, o que demonstra afinamento nas políticas de corte em investimentos sociais, isto é, a reforma do ensino médio é uma adequação política à redução imposta pelo Emenda Constitucional no 95/2016.

A capacidade da escola de trabalhar em prol de uma formação que dá base ao esclarecimento político dentro do contexto da Reforma do Ensino Médio esbarra no interesse do capital inserir-se profundamente em todas as vias culturais e encontrou, dentro da realidade brasileira, terreno fértil.

Ao invés de melhorar as condições de trabalho docente e as estruturas físicas das escolas, a reforma aceitará "notório saber" tanto de profissionais quanto de empresas de ensino para atuar na educação pública, de modo a diminuir os gastos com a educação pública e movimentar a economia investindo no setor privado, mostrando que, conforme afirmou Habermas (2015) gastos com a educação e tudo mais que envolve o que Estado de bem-estar social podem ser cortados em momentos de crise econômica.

\section{Conclusão}

A reforma do ensino médio brasileiro pode ser considerada um dos desdobramentos mais torrenciais do golpe parlamentar ocorrido em 2016. Por meio da modalidade educação profissional e técnica o atual governo temeroso busca não apenas responder aos anseios do Banco Mundial, como também cria condições para o desmonte da educação básica, por meio de minimização do formação crítica e fomento à privatização, ora de espaços físicos, ora de serviços educacionais.

Modificações como as impostas ao Ensino Médio por meio da Lei no 13.415/2017 demonstram que a educação ao ser instrumentalizada por um estado tecnocrata afinado com os interesses do mercado capitalista trabalha em prol do esvaziamento do pensamento crítico e a diminuição dos espaços públicos deliberativos dentro das escolas.

Sob esse contexto imposto é necessário a resistência dos professores e a tomada de espaços de decisão acerca dos rumos da educação, sendo imprescindível que a atuação pedagógica defenda o pensamento crítico em todos os níveis de ensino.

A reforma do ensino médio afeta não apenas a educação básica, atinge também os cursos de formação docente e as formas de financiamento público que tende a ser gradativamente menor, pois 
foram criadas em consonância com o congelamento dos gastos públicos por duas décadas, dessa forma fica clara que os cortes sociais foram operados com sincronia para o fortalecimento da ideia de um estado mínimo.

\section{Referências}

BRASIL. EM no 00084/2016/MEC. MEC. Brasilia, 2016. Disponível em: <http://www.planalto.gov.br/ccivil_03/_ato2015-2018/2016/Exm/Exm-MP-746-16.pdf>. Acesso em: 23 set. 2017.

Lei $\mathbf{n}^{\circ}$ 9.394, de 20 de dezembro de 1996. Estabelece as diretrizes e bases da educação nacional. Disponível em: <http://www.planalto.gov.br/ccivil 03/leis/19394.htm>. Acesso em: 25 nov. 2017.

Lei $\mathbf{n}^{\mathbf{0}} \mathbf{1 3 . 4 1 5}$, de 16 de fevereiro de 2017. Altera as Leis nos 9.394, de 20 de dezembro de 1996, que estabelece as diretrizes e bases da educação nacional, e 11.494, de 20 de junho 2007, que regulamenta o Fundo de Manutenção e Desenvolvimento da Educação Básica e de Valorização dos Profissionais da Educação, a Consolidação das Leis do Trabalho - CLT, aprovada pelo Decreto-Lei no 5.452, de 1o de maio de 1943, e o Decreto-Lei no 236, de 28 de fevereiro de 1967; revoga a Lei no 11.161, de 5 de agosto de 2005; e institui a Política de Fomento à Implementação de Escolas de Ensino Médio em Tempo Integral. Disponível em: <http://www.planalto.gov.br/ccivil_03/_ato 2015-

2018/2017/lei/113415.htm>. Acesso em: 12 out. 2017.

DRABACH, N. P.; SOUZA, A. R. de. Leituras sobre a gestão democrática e o "gerencialismo" na/da Educação no Brasil. Revista Pedagógica. v.16, n.33, p. 221-248, jul./dez. 2014.

GAWRYSZEWSKI, B. Crises capitalistas e conjuntura de contrarreformas: qual o lugar do Ensino Médio? Revista Pedagógica. v. 19, n. 42, p. 83-106, set./dez. 2017.

HABERMAS, J. Técnica e Ciência como "Ideologia". Tradução por Artur Mourão. Lisboa: Edições 70 LDA, 2013.

A Nova Obscuridade: pequenos escritos políticos. Tradução por Luiz Repa. São Paulo: Editora Unesp, 2015.

LEHER, Roberto; VITTOÓRIA, Paolo; MOTTA, Vania Cardoso. EDUCAÇÃO E MERCANTILIZAÇÃO EM MEIO À TORMENTA POLÍTICO-ECONỒMICA DO

BRASIL. Germinal: Marxismo e Educação em Debate, Salvador, v. 9, n. 1, p. 14-24, mai. 2017. ISSN 2175-5604. Disponível em: <https://portalseer.ufba.br/index.php/revistagerminal/article/view/21792>. Acesso em: 18 Mar. 2019. doi:http://dx.doi.org/10.9771/gmed.v9i1.21792.

LOWY, M. Da tragédia à farsa: o golpe de 2016 no Brasil. In: JINKINS, I.; DORIA, K.; CLETO, M. (Orgs). Por que gritamos golpe: Para entender o impeachment e a crise. São Paulo: Boitempo, 2016. p. 55-59.

MARSIGLIA, Ana Carolina Galvão et al. A BASE NACIONAL COMUM CURRICULAR: UM NOVO EPISÓDIO DE ESVAZIAMENTO DA ESCOLA NO BRASIL. Germinal: Marxismo e Educação em Debate, Salvador, v. 9, n. 1, p. 107-121, mai. 2017. ISSN 2175-5604. Disponível em: <https://portalseer.ufba.br/index.php/revistagerminal/article/view/21835>. Acesso em: 18 Mar. 2019. doi:http://dx.doi.org/10.9771/gmed.v9i1.21835.

RAMOS, M. N.; FRIGOTTO, G. Medida provisória 746/2016: a contra-reforma do ensino médio do golpe de Estado de 31 de agosto de 2016. Revista HISTEDBR On-line. v. 16, n. 70, p. 30-48, dez. 2016.

REIS, L. N. G. dos; MARTINS, M. T; ROSA, D. A. Educação Ambiental frente à Reforma do Ensino Médio no Brasil. Periódico Ambiental da Alta Paulista. v. 13, n. 2, p. 78-89, 2017. 
SILVA, M. R. Currículo, ensino médio e BNCC: Um cenário de disputas. Revista Retratos da Escola. v. 9, n. 17, p. 367-379, jul./dez. 2015.

\section{Notas:}

1 Pedagoga da Seduc-AM. Aluna do Programa de Pós-Graduação em Educação e Ensino de Ciências na Amazônia da Universidade do Estado do Amazonas. Email: nay.ped@hotmail.com

2 Doutor em Educação- Unicamp. Orientador de Mestrado do Programa de Pós-Graduação em Educação e Ensino de Ciências na Amazônia da Universidade do Estado do Amazonas. Email: semogcosta@yahoo.com.br

3 Professora de Educação Especial da Seduc-AM Aluna do Programa de Pós-Graduação em Educação e Ensino de Ciências na Amazônia da Universidade do Estado do Amazonas. Email: : naranjo.paulac@gmail.com

${ }_{4}$ Pedagoga e Formadora na Semed-Manaus. Aluna do Programa de Pós-Graduação em Educação e Ensino de Ciências na Amazônia da Universidade do Estado do Amazonas. Email: anaclaudia_salima@hotmail.com 